\title{
Modern Challenges for Universities
}

\author{
Tatiana Klyachko and Vladimir Mau
}

During the COVID-19 crisis, which has turned out to be an unprecedented challenge for higher education all over the world, IAU has become a platform that unites the efforts of universities and other educational institutions and also encourages the collaborative search for solutions to the problems they face. The communication mechanisms developed during this period, the global research conducted, and various web resources have significantly enriched the discourse in higher education. But most importantly, a solid foundation for the future strategic rethinking of the management of universities has been laid.

We have realised that in the post-COVID world universities will be changing dynamically, and they will need new values to operate. For instance, IAU was one of the first organisations to draw attention to universities' contribution to the SDGs and, undoubtedly, will continue to develop this topic. IAU's role as an expert and consultant has been constantly praised during the crisis. The series of online webinars with leading experts in higher education from different countries and regions have shown both general and individual challenges that universities have faced. As a result of IAU research activities, a broad vision of the situation in global higher education has been presented, and recommendations have been developed that will help universities survive in the post-pandemic period. In the future, we can expect an avid interest in IAU's reports on topical issues and transformations in higher education all over the world. All the more so because universities will have to once again position themselves in the rapidly changing world.

T. Klyachko $(\varangle) \cdot$ V. Mau

The Russian Presidential Academy of National Economy and Public Administration,

Moscow, Russia

e-mail: tlk@ranepa.ru

V. Mau

e-mail: rector@ranepa.ru 
Universities always face both external and internal challenges. These challenges can be narrowed down to the following ones:

1. Exceptional labour market dynamism including the emergence of new professions;

2. Transformation of education into one of the key drivers of economic growth and increase in demand for quality education;

3. Rapid emergence and development of new educational technologies that must be quickly adopted in professional education;

4. Stiffer competition for the best academic staff that can also be faced from foreign universities;

5. Technological base and educational environment quality are the main factors of universities' competitiveness;

6. Scientific development through global network cooperation;

7. Organisations, companies and countries are competing with each other in terms of the quality of both management models and management teams. The importance and development of universities' management;

8. Student and staff mobility is becoming a factor in the effective development of education;

9. Maintenance of universities' dynamic development and their financial stability.

The COVID-19 pandemic and enforced shift to distance learning have revealed a host of issues and risks to higher education development. Firstly, it is the awareness of vulnerability of mass systems like health service or education in the face of such shocks. Secondly, it is the understanding of the necessity of having capacity both in higher education and education at other levels in order to protect the systems from stress overload. The development of distance learning technologies and universities' digital environment has become a mechanism for creating spare capacity that can be quickly deployed to undertake a significant proportion of the overload. At the same time, the pandemic has shown that this capacity is not enough, and its deficit leads to differences in accessibility to quality education, not only between different universities but within universities.

While recovering from the pandemic, universities will have to become aware of their capacity deficit and build a brand-new configuration of educational activities which will successfully combine face-to-face teaching, distance learning technologies and free online courses. Whether the importance of face-to-face learning decreases is a vital question. On the one hand, the reaction to the stressful shift to distance learning can be the wish to get back to normal, which will lead to overvaluing face-to-face teacher-student interaction for some time. On the other hand, there can be overall awareness of the undervaluation of distance learning technologies and their usefulness for global network cooperation between universities and for student and staff academic mobility intensification. Naturally, it will require brand new managerial and economic decisions which will gradually make the system of higher education increasingly global.

There is a more difficult question, though: how technological shifts and new opportunities influence the relevance of specific professions? Surveys among 15-year-old 
schoolchildren, carried out by OECD, show that modern teenagers paradoxically tend to choose rather traditional professions like doctors, teachers, military personnel and police officers.

What does it all mean for universities? First of all, they must be ready to deal with the fact that young people's job preferences will change over time. This is why it is vital that universities provide a wide range of non-specific disciplines to let their students form their preferences more clearly. For this reason, programmes in the liberal arts will be developed and attract more and more students.

The development of practice-oriented education is also a widely discussed topic because it allows recent graduates to become immediately engaged in work. However, this rapid change of technologies makes this strategy risky, to say the least. On the contrary, the fundamentality of university education should be the underlying principle because only this strategy will help students become successful. Fundamental knowledge can be used as a basis on which we can, so to say, 'put' practiceoriented, momentary knowledge. In fact, we must prepare students for the long run, not for a short run in life. It is also vital that universities develop ranges of additional courses to make education truly continuing. Most of these courses will be developed as online-courses, i.e. MOOCs. In addition to that, MOOCs allow students to acquire the necessary knowledge, but only if (1) students understand what courses they need, and (2) all necessary courses can be found among MOOCs. This is why distance learning courses are also necessary, when students contact universities and get the knowledge they need, combining the use of MOOCs with distance learning which can be more personalised than MOOCs. Distance classes and consultations can be conducted both for individuals and small groups when a teacher can take the interests and needs of their students into consideration.

We can, therefore, say that a university is (1) a wide range of courses, especially in the first two years of undergraduate studies; (2) fundamental and thus complex education; (3) continuing education, i.e. the ability to offer and deliver programmes for specialists at various stages of their career.

At the same time, university is a full-time education, connected with MOOCs and distance learning. However, the ratio between the components can vary with years of study, levels of higher education and, later, of postgraduate education.

It should be stressed that full-time face-to-face education will be preserved even though the system of higher education has learned the lesson of the mass and rapid launch of distance learning courses in 2020. This is due to the fact that the university is not only a place of knowledge acquisition but also a place for socialisation, human interaction and common values and trust development.

In short, in order to incorporate all the above-mentioned components, a modern university should develop network cooperation: the stronger the network, the bigger a course range is, as well as the capability of MOOCs development and distance education. It is safe to say that a university of the future is a networked university or, to be more exact, a network of universities united by a common mission and providing their students and trainees with a huge range of educational, cultural and social practices. 
However, the development of strong networks does not mean that universities will not compete for students or professors, eminent scientists, who create and strengthen universities' reputations. In the post-pandemic world, this competition will get more intense because now it has become clear that a teacher or professor who can attract lots of students conducting the classes online allows the university to develop both extensively and intensively. Moreover, in addition to the competition for students, best professors and renowned researchers, one should add the competition for universities integrated into specific university networks. It is currently hard to assess how this institutional competition will influence the world's system of higher education.

There is one more factor that should be taken into consideration when it comes to universities' future. These are opportunities that bring new technologies into universities to advance science. These days it is vital to form university networks for research/projects implementation. Then the following question arises: will this network coincide with the educational one or can a university be included in different networks regarding education and science? At the moment, inclusion of the university into one university network for education, and into another one for science seems rather exotic, but nevertheless, this can turn out to be quite effective. Subsequently, the competition for including a certain university into a certain scientific university network may intensify as well. It is only natural to ask, then, why the competition will take place in this field and why it is not allowed to include everyone into the network. In fact, this option is also possible. However, extremely rapid growth of the network is dangerous from the point of view of its sustainability and effectiveness. If a certain regionalisation of global economy takes place, it is possible to suppose that regional university networks will appear first-both educational and scientific (educational-scientific), which will try to strengthen themselves drawing universities from one regional network to another. That is why it seems that at the beginning of the process there will be tough competition in the development of university networks.

The entry of non-university elements into the above-mentioned networks will become an important factor in universities' development. It can be Internet companies that develop online education, various platforms with educational courses, marketplaces of expert and consulting services. The good thing about the digital world is that it brings different activities together, shortening space and expanding the opportunities of communication both between individual universities and within university networks.

It is also necessary to take into account that resources, including modern educational technologies, available to some universities may be unavailable or not easily available to other ones. As a result, within national borders and in the world in general, differentiation between universities will take place based on their level of digitalisation. This will strongly influence the quality of higher education that will be available in different countries to different social groups. Currently, we are already witnessing this differentiation, but the existing division between universities will gain one more essential dimension. For this reason, we are facing the problem of reducing this differentiation and the mechanisms that will allow us to overcome it so that an increasing number of students gain access to quality higher education. Distance education technologies can play a positive role, giving access to their digital resources to 
other universities, expanding programmes of academic and staff mobility. However, whereas within university networks academic mobility is predominantly horizontal, in this case, it is vertical: when students from weaker universities get an opportunity to attend - face-to-face or remotely—some courses provided by stronger, especially in terms of digitalisation, universities.

The development of university networks and horizontal and vertical academic mobility will demand further training for universities' management teams because they will have to solve ever-complicating problems amidst quickening technological and social changes. It is the quality of management that will become a decisive factor in the development of universities. Therefore, one can expect an increase of another type of competition: in terms of the quality of university management, financial health, and financial stability of the university.

Universities' transition to a new level of development will demand new resources. For a long time, there was an idea that the development of online education would reduce the costs of universities. The year 2020 has shown that distance learning involving online courses is still much more expensive than its traditional form. Currently, universities around the world are in a rather difficult financial situation. Therefore, increasing their financial stability in the new conditions is becoming an extremely urgent problem that will have to be addressed amidst the growing uncertainty of the future.

Tatiana Klyachko is Director of the Center for the Economics of Continuing Education, RANEPA, Russia. She specialises in education economics, as well as in managing and reforming this area. She is the author of more than 200 papers devoted to various issues of education system development, which have been published both in Russian and in English.

Vladimir Mau is the Rector of The Russian Presidential Academy of National Economy and Public Administration (RANEPA). He is a specialist in political economy, economic history and economics in transition. He is the author of numerous articles, books and textbooks. His studies have been published in Russian, English, French, German and Italian.

Open Access This chapter is licensed under the terms of the Creative Commons Attribution 4.0 International License (http://creativecommons.org/licenses/by/4.0/), which permits use, sharing, adaptation, distribution and reproduction in any medium or format, as long as you give appropriate credit to the original author(s) and the source, provide a link to the Creative Commons license and indicate if changes were made.

The images or other third party material in this chapter are included in the chapter's Creative Commons license, unless indicated otherwise in a credit line to the material. If material is not included in the chapter's Creative Commons license and your intended use is not permitted by statutory regulation or exceeds the permitted use, you will need to obtain permission directly from the copyright holder.

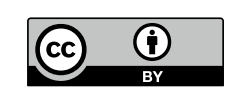

